\section{(6) OPEN ACCESS}

\title{
Work injury risk by time of day in two population-based data sources
}

\author{
Cameron A Mustard, ${ }^{1,2}$ Andrea Chambers, ${ }^{1}$ Christopher McLeod, ${ }^{3}$ Amber Bielecky, ${ }^{1}$ \\ Peter M Smith ${ }^{1,2,4}$
}

\begin{abstract}
- Additional supplementary figures are published online only. To view these files please visit the journal online (http:// dx.doi.org/10.1136/oemed2012-100920).

${ }^{1}$ Institute for Work \& Health, Toronto, Ontario, Canada ${ }^{2}$ Dalla Lana School of Public Health, University of Toronto, Toronto, Ontario, Canada ${ }^{3}$ UBC Centre for Health Services and Policy Research, University of British Columbia, Vancouver, British Columbia, Canada

${ }^{4}$ School of Public Health and Preventive Medicine, Monash University, Melbourne, Victoria, Australia
\end{abstract}

\section{Correspondence to} Dr Cameron A Mustard, Institute for Work \& Health, 481 University Ave, Suite 800, Toronto, Ontario, Canada M5G 2E9; cmustard@iwh.on.ca

Received 15 May 2012 Revised 25 July 2012 Accepted 15 August 2012 Published Online First 26 September 2012

\footnotetext{
To cite: Mustard CA, Chambers A, McLeod C, et al. Occup Environ Med 2013, 70, 49-56.
}

\section{ABSTRACT}

Objective To estimate the rate of work injury over the $24 \mathrm{~h}$ clock in Ontario workers over 5 years (2004-2008). Methods A cross-sectional, observational study of work-related injury and illness was conducted for a population of occupationally active adults using two independent data sources (lost-time compensation claims and emergency department encounter records). Hours worked annually by the Ontario labour force by time of day, age, gender and occupation were estimated from population-based surveys.

Results There was an approximately $40 \%$ higher incidence of emergency department visits for work-related conditions than of lost-time workers' compensation claims (707 933 emergency department records and 457141 lost-time claims). For men and women and across all age groups, there was an elevated risk of work-related injury or illness in the evening, night and early morning periods in both administrative data sources. This elevated risk was consistently observed across manual, mixed and non-manual occupational groups. The fraction of lost-time compensation claims that can be attributed to elevated risk of work injury in evening or night work schedules is $12.5 \%$ for women and $5.8 \%$ for men.

Conclusions Despite the high prevalence of employment in non-daytime work schedules in developed economies, the work injury hazards associated with evening and night schedules remain relatively invisible. This study has demonstrated the feasibility of using administrative data sources to enhance capacity to conduct surveillance of work injury risk by time of day. More sophisticated aetiological research is needed to understand the specific mechanisms of hazards associated with non-regular work hours.

\section{INTRODUCTION}

More than 25\% of full-time workers in Canada work some form of shift schedule, performing work in the evening, night or early morning periods. ${ }^{1}{ }^{2}$ There is an extensive literature on the relationship between work hours (including shift work) and adverse consequences for workers' health ${ }^{3-5}$ with consistent evidence of elevated risk associated with work schedules involving employment in the evening or night. ${ }^{6-20}$ These risks are generally understood to arise from the individual or joint influence of worker fatigue (due to sleep disturbance or long work hours) and typically

\section{What this paper adds}

- An elevated risk of work injury is associated with evening or night work schedules.

- This elevated risk is understood to arise from worker fatigue and from typically lower levels of supervision and co-worker support during non-daytime work schedules.

- Approximately $25 \%$ of full-time workers in North America work some form of shift schedule.

- Despite the high prevalence of evening and night work schedules, there is limited population-level surveillance of the risk of work injury by time of day.

- This study demonstrates the feasibility of work injury risk by time of day and estimates that $12.5 \%$ of work injuries to women and $5.8 \%$ of work injuries to men can be attributed to the elevated risk of work injury in evening or night work schedules.

lower levels of supervision and co-worker support during non-daytime work schedules.

A review published in 2004 found evidence of deteriorating performance on psychophysiological tests and increased risk of injury with longer shift durations and an elevated risk of injury for evening and night shifts compared to day shifts. ${ }^{21}$ Two recent population-based studies have reported findings consistent with this earlier review. A Canadian study found night shift work was associated with an elevated risk of occupational injury and estimated that the excess burden of work injury attributed to shift work was $14 \%$ for women and $8 \%$ for men. ${ }^{8}$ A study based on the US National Longitudinal Survey of Youth (1987-2000) examining the association between different shift work schedules and the incidence of self-reported work injury and illness in a sample of young adults aged 22-30 found that night, evening, rotating and irregular shifts were all associated with an increased risk of occupational injury or illness compared with regular day shifts. ${ }^{7}$

Despite the high prevalence of shift work schedules in north America, limited information on work hours relative to the $24 \mathrm{~h}$ clock is available. In Canada and the USA, labour market surveys conducted by national statistical agencies routinely measure hours of work, typically in the past week, 
for large, representative samples of labour force participants. These survey sources, however, do not collect information on work hours relative to the $24 \mathrm{~h}$ clock. In addition to the challenge of measuring working hours over the $24 \mathrm{~h}$ clock, there is a parallel challenge in measuring individual work demands for typical day, evening and night shifts. Shift work may be associated with work demands that are less than, similar to, or greater than work demands during regular daytime schedules. In addition to differences in work demands, there will often be differences in the availability of supervisors and co-workers between daytime, evening and night shift schedules. ${ }^{6}$

Despite the established evidence for an elevated risk of work injury in non-standard work schedules, there is limited surveillance capacity in most countries to monitor and describe the risk of work injury by time of day. ${ }^{22}$ To address this surveillance deficit, the objective of this observational study was to describe the incidence of work injury in Ontario over the period 20042008 by hour of the $24 \mathrm{~h}$ clock in two population-based administrative data sources. Consistent with the evidence summarised in the introduction, the study expected to document an elevated risk of work injury during evening and night periods in both data sources.

\section{METHODS}

\section{Study design}

Records of work-related injury or illness for a complete population of occupationally active adults aged 15-64 in the province of Ontario were obtained from two independent sources: a census of allowed lost-time compensation claims registered with the Ontario Workplace Safety \& Insurance Board and a census of emergency department encounter records where the injury or illness was attributed to a workplace cause. Estimates of hours worked annually for the Ontario labour force by time of day, age, gender and occupation were derived from two survey sources.

\section{Data sources}

Lost-time compensation claims

Lost-time workers' compensation claim records were obtained from the Ontario Workplace Safety \& Insurance Board. Lost-time claim records (claims that involve payments for wage replacement benefits) contain information on date and time of injury, the employer's economic sector, the gender, birth date and occupation of the injured worker, and characteristics of the nature of, and event leading to, injury. ${ }^{23}$

\section{Emergency department encounter records}

The Ontario Ministry of Health and Long-Term Care has mandated the reporting of all emergency department visits to the National Ambulatory Care Reporting System (NACRS) since July $2000 .^{24}$ Emergency department records where the 'responsibility for payment' code indicated the Workplace Safety and Insurance Board for the period January 2004 to December 2008 were obtained from NACRS. Responsibility for payment refers to the clinical determination of a work-related cause of injury or illness presenting to the emergency department and is independent of the registration or acceptance of a workers' compensation claim. ${ }^{22}$ Variables included in the extracted records were: gender, birth date, visit type, visit date, triage time and a series of up to 10 fields documenting the main problem and the external cause of injury.

For the purposes of this study, we defined eight categories of injury event that were concordant in the Z-795 standard and ICD-10-CA classification scheme applied in the NACRS data. ${ }^{22}$
In addition, a three-level occupational categorisation scheme developed by the Institut de recherché Robert-Sauvé du travail was implemented to classify occupations as manual, non-manual or mixed. ${ }^{25}$

Denominator estimates of hours worked were based on data from two Statistics Canada surveys: the Labour Force Survey (LFS) (2004-2008) and the General Social Survey (GSS) (Cycle 19-2005). ${ }^{26} 27$ The LFS was used to derive estimates of hours worked (2004-2008) in Ontario, stratified by gender, age group and the three-level occupational classification (manual, mixed or non-manual). To distribute hours of work from the LFS across the $24 \mathrm{~h}$ clock, we used information from the GSS (Cycle 19). The GSS periodically collects information on time use, using a diary format. Each respondent to the GSS is randomly assigned a day of the week and asked to report their activities over a $24 \mathrm{~h}$ period. For the purposes of this study, activity codes that identified work-related activities were selected. Studies of the reliability of daily time use diary records indicate that this measurement method is appropriate for deriving estimates of work time. ${ }^{28}$ The GSS was used to create a proportional matrix distributing the total number of minutes of work-related activity across the $24 \mathrm{~h}$ clock stratified by day of the week, gender, age group and the three-level occupational classification. The estimates from the LFS, stratified by gender, age and occupational group, were then applied to these matrices.

We performed a final adjustment for denominator estimates used in estimating the rates of lost-time claims per $200000 \mathrm{~h}$ worked to account for differences in coverage between the WSIB and the Ontario Health Insurance Plan. Approximately $30 \%$ of the Ontario labour force is in employment relationships that are excluded from coverage by the WSIB. Within the three occupational categories (manual, mixed and non-manual occupations), LFS estimates were adjusted by excluding selfemployed workers and workers employed in economic sectors that were not required to register for workers' compensation insurance. ${ }^{29}$ The adjusted denominator estimates were used to calculate age, sex and occupation-specific incidence rates for lost-time compensation claims.

\section{Analytical methods}

Rates were calculated by dividing the total number of lost-time claims or work-related emergency department visits (20042008) by the number of hours worked in Ontario over this time period. Rates were expressed per $200000 \mathrm{~h}$ worked and 95\% CIs were calculated. ${ }^{30}$ Relative risk estimates (and 95\% CIs) were computed from negative binomial regression models with the period 12:00-13:59 as the reference. To estimate the influence of occupational differences in exposure to work schedules in evening and night periods, we stratified the analysis of lost-time claims by three occupational categories (manual, nonmanual and mixed) using exposure time measured in $2 \mathrm{~h}$ intervals. The fractions of work injuries attributable to shift work exposure were calculated for men and women separately using information on the prevalence of workers exposed to shift work and the relative risk of work injury during evening and night hours compared to the period $08: 00-18: 00$.

\section{RESULTS}

The incidence of emergency department visits for work-related conditions was approximately $40 \%$ higher than the incidence of lost-time workers' compensation claims (table 1). A total of 75 emergency department records were missing information on triage time $(0.01 \%)$ and 97862 lost-time claims (21.4\%) were missing information on time of injury. Lost-time claimants with 
Table 1 Distribution of lost-time claims and emergency department records by gender, age, occupation and injury event (2004-2008)

\begin{tabular}{|c|c|c|c|c|c|c|c|c|}
\hline \multirow[b]{3}{*}{ Total } & \multicolumn{6}{|c|}{ Lost-time claims } & \multicolumn{2}{|c|}{$\begin{array}{l}\text { Emergency } \\
\text { department records }\end{array}$} \\
\hline & \multicolumn{2}{|c|}{ Time of injury missing } & \multicolumn{2}{|c|}{$\begin{array}{l}\text { Time of injury not } \\
\text { missing }\end{array}$} & \multicolumn{2}{|l|}{ Total } & \multicolumn{2}{|l|}{ Total } \\
\hline & $\begin{array}{l}N \\
97862\end{array}$ & $\begin{array}{l}\text { Row \% } \\
21.4\end{array}$ & $\begin{array}{l}N \\
359279\end{array}$ & $\begin{array}{l}\text { Row \% } \\
78.6\end{array}$ & $\begin{array}{l}N \\
457141\end{array}$ & $\begin{array}{l}\text { Col \% } \\
100.0\end{array}$ & $\begin{array}{l}N \\
707933\end{array}$ & $\begin{array}{l}\text { Col \% } \\
100.0\end{array}$ \\
\hline \multicolumn{9}{|l|}{ Gender } \\
\hline Male & 60727 & 21.1 & 226774 & 78.9 & 287501 & 62.9 & 521062 & 73.6 \\
\hline Female & 37133 & 21.9 & 132505 & 78.1 & 169638 & 37.1 & 186844 & 26.4 \\
\hline Missing* & - & - & - & - & - & - & 27 & 0 \\
\hline \multicolumn{9}{|l|}{ Age (years) } \\
\hline 15-24 & 9840 & 16.8 & 48829 & 83.2 & 58669 & 12.8 & 149391 & 21.1 \\
\hline $25-34$ & 15999 & 17.4 & 76170 & 82.6 & 92169 & 20.2 & 177980 & 25.1 \\
\hline $35-44$ & 24630 & 20.0 & 98824 & 80.0 & 123454 & 27.0 & 181281 & 25.6 \\
\hline $45-54$ & 26154 & 22.2 & 91660 & 77.8 & 117814 & 25.8 & 142383 & 20.1 \\
\hline $55-64$ & 21237 & 32.7 & 43794 & 67.3 & 65031 & 14.2 & 56898 & 8.0 \\
\hline Missing ${ }^{*}$ & - & - & - & - & - & - & 0 & 0 \\
\hline \multicolumn{9}{|l|}{ Occupation } \\
\hline Manual & 47733 & 19.0 & 202956 & 81.0 & 250689 & 54.8 & NA & NA \\
\hline Mixed & 20222 & 16.0 & 105956 & 84.0 & 126178 & 27.6 & NA & NA \\
\hline Non-manual & 10387 & 20.2 & 40963 & 79.8 & 51350 & 11.2 & NA & NA \\
\hline Missing & 19520 & 67.5 & 9404 & 32.5 & 28924 & 6.3 & NA & NA \\
\hline \multicolumn{9}{|l|}{ Event } \\
\hline Bodily reaction and exertion & 50269 & 24.3 & 156474 & 75.7 & 206743 & 45.2 & 94913 & 13.4 \\
\hline Contact with objects/equipment & 13767 & 13.1 & 91316 & 86.9 & 105083 & 23.0 & 319979 & 45.2 \\
\hline Falls & 9211 & 11.5 & 70724 & 88.5 & 79935 & 17.5 & 87252 & 12.3 \\
\hline Exposure to harmful substances & 6066 & 27.6 & 15937 & 72.4 & 22003 & 4.8 & 62647 & 8.9 \\
\hline Transportation events & 1639 & 11.3 & 12816 & 88.7 & 14455 & 3.2 & 16319 & 2.3 \\
\hline Assaults and violence & 1134 & 10.3 & 9870 & 89.7 & 11004 & 2.4 & 8325 & 1.2 \\
\hline Fires and explosions & 249 & 13.1 & 1652 & 86.9 & 1901 & 0.4 & 3104 & 0.4 \\
\hline Other events/exposure unknown & 474 & 49.2 & 490 & 50.8 & 964 & 0.2 & 3864 & 0.5 \\
\hline Missing & 15053 & 100.0 & 0 & 0.0 & 15053 & 3.3 & 111530 & 15.8 \\
\hline
\end{tabular}

${ }^{*}$ Cell counts with values less than 5 have been suppressed.

missing information on time of injury were more likely to be older and the injury event was more likely to be associated with bodily reaction/exertion or exposure to harmful substances.

There were substantial differences between the lost-time claims and the emergency department records in the event responsible for the injury. The largest proportion of emergency department records were associated with injuries caused by contact with objects or equipment $(45.2 \%$ of all emergency department visits). In contrast, the largest proportion of losttime claims were associated with injuries arising from musculoskeletal strain without a traumatic cause (45.2\%). The number of compensation claims and emergency department visits for injuries arising from falls, from motor vehicle collisions and from assaults or violence were broadly similar.

Figure 1 compares the rate of injury per $200000 \mathrm{~h}$ worked across the $24 \mathrm{~h}$ clock between the emergency department records and the lost-time claim records. The estimated injury rates in the two data sources are generally similar over the period $05: 00$ and 16:00. In both data sources, the incidence of work-related injury is elevated in the evening hours $(17: 00-$ $24: 00)$ and in the early morning hours (00:00-05:00), with higher incidence rates recorded in the emergency department data than the lost-time claim data.Table 2 reports the relative risk of work injury in the two data sources, stratified by age and gender. Across all age groups and for both men and women,

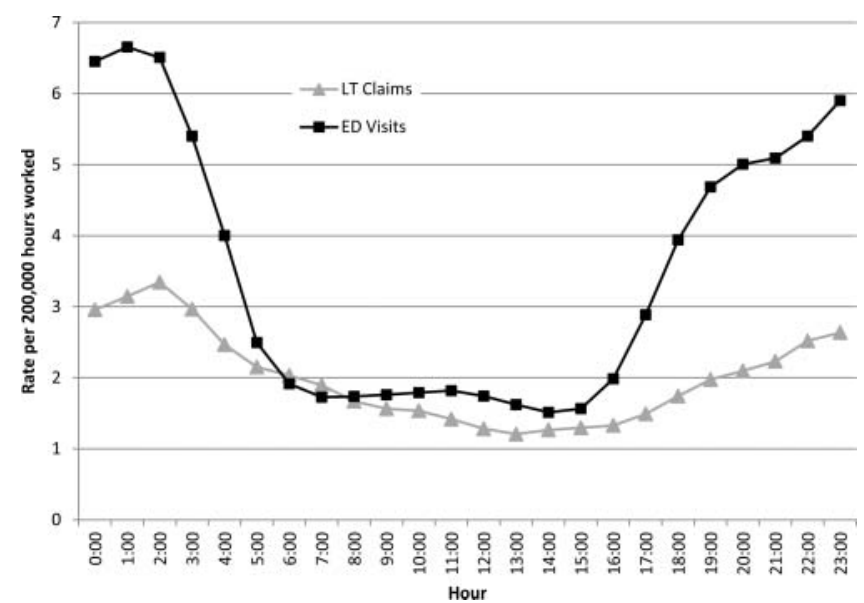

Figure 1 Rate of work injury per $200000 \mathrm{~h}$ worked in Ontario (2004-2008) by data source and hour. ED visits, emergency department visits (National Ambulatory Care Reporting System); LT claims, lost-time claims (WSIB). Each hour interval corresponds to one full hour interval. For example, 1:00 includes all injuries between 1:00 and 1:59. Rates are based on a $3 \mathrm{~h}$ weighted average. Note that 97860 lost-time claims are excluded due to missing information on time of injury. 
Table 2 Relative risk $(95 \% \mathrm{Cl})$ of injury in Ontario (2004-2008) relative to $12: 00-13: 59$ by gender, data source, age and $2 \mathrm{~h}$ time intervals

\begin{tabular}{|c|c|c|c|c|c|c|c|c|c|c|}
\hline \multirow[b]{2}{*}{ Hour } & \multicolumn{5}{|l|}{ Lost-time claims } & \multicolumn{5}{|c|}{ Emergency department records } \\
\hline & Aged 15-24 & Aged 25-34 & Aged 35-44 & Aged 45-54 & Aged 55-64 & Aged 15-24 & Aged 25-34 & Aged 35-44 & Aged 45-54 & Aged 55-64 \\
\hline \multicolumn{11}{|l|}{ Males } \\
\hline $12: 00-1: 59$ & 1.25 (1.03 to 1.51$)$ & 2.10 (1.76 to 2.50$)$ & 2.56 (2.24 to 2.91$)$ & 2.99 (2.69 to 3.32 ) & 2.50 (2.16 to 2.89 ) & 2.53 (2.13 to 3.00$)$ & 3.32 (2.82 to 3.91$)$ & 3.43 (2.96 to 3.97$)$ & 3.44 (3.09 to 3.84 ) & 2.88 (2.61 to 3.19$)$ \\
\hline $2: 00-3: 59$ & 1.58 (1.24 to 2.04$)$ & 2.07 (1.68 to 2.56 ) & 2.63 (2.28 to 3.03 ) & 3.18 (2.79 to 3.63 ) & 2.93 (2.52 to 3.42 ) & 2.50 (2.03 to 3.07 ) & 2.97 (2.48 to 3.55 ) & 3.09 (2.70 to 3.55$)$ & 2.98 (2.65 to 3.36 ) & 2.45 (2.21 to 2.71$)$ \\
\hline $4: 00-5: 59$ & 1.04 (0.83 to 1.30$)$ & 1.24 (1.02 to 1.50$)$ & 1.65 (1.44 to 1.88$)$ & 1.84 (1.66 to 2.04$)$ & 1.66 (1.44 to 1.91$)$ & 1.08 (0.86 to 1.37$)$ & 1.28 (1.06 to 1.54$)$ & 1.33 (1.16 to 1.52$)$ & 1.34 (1.20 to 1.50$)$ & $1.09(0.98$ to 1.21$)$ \\
\hline $6: 00-7: 59$ & 1.05 (0.83 to 1.32$)$ & 1.35 (1.14 to 1.58$)$ & 1.54 (1.37 to 1.74$)$ & 1.67 (1.53 to 1.82$)$ & 1.58 (1.41 to 1.77$)$ & 0.66 (0.59 to 0.75$)$ & $0.83(0.74$ to 0.93$)$ & $0.86(0.76$ to 0.97$)$ & 0.98 (0.90 to 1.06$)$ & 0.92 (0.86 to 0.97$)$ \\
\hline $8: 00-9: 59$ & 1.19 (0.97 to 1.47$)$ & 1.36 (1.16 to 1.59$)$ & 1.39 (1.23 to 1.57$)$ & 1.38 (1.26 to 1.52$)$ & 1.35 (1.22 to 1.49$)$ & 0.93 (0.82 to 1.04$)$ & 0.98 (0.89 to 1.09 ) & 1.05 (0.94 to 1.17$)$ & 1.11 (1.05 to 1.19$)$ & $1.13(1.08$ to 1.18$)$ \\
\hline $10: 00-11: 59$ & 1.38 (1.14 to 1.67$)$ & 1.45 (1.24 to 1.69$)$ & 1.43 (1.25 to 1.64$)$ & 1.46 (1.33 to 1.59$)$ & 1.48 (1.34 to 1.63$)$ & 1.06 (0.95 to 1.18$)$ & 1.09 (0.98 to 1.20$)$ & 1.13 (1.02 to 1.25$)$ & 1.16 (1.09 to 1.23$)$ & 1.13 (1.07 to 1.18$)$ \\
\hline $12: 00-13: 59$ & 000 & 000 & 000 & 000 & 000 & 000 & 000 & 000 & 000 & 000 \\
\hline $14: 00-15: 59$ & 1.15 (0.96 to 1.38$)$ & 1.17 (1.01 to 1.36$)$ & 1.13 (0.98 to 1.30$)$ & 1.20 (1.09 to 1.32$)$ & 1.23 (1.11 to 1.35$)$ & 0.90 (0.82 to 0.99$)$ & 0.84 (0.76 to 0.93 ) & 0.83 (0.75 to 0.92$)$ & 0.85 (0.81 to 0.90$)$ & 0.88 (0.82 to 0.93$)$ \\
\hline $16: 00-17: 59$ & 1.03 (0.85 to 1.25 ) & 1.16 (0.98 to 1.37 ) & 1.10 (0.96 to 1.26$)$ & 1.15 (1.06 to 1.26$)$ & 1.18 (1.03 to 1.34$)$ & 1.01 (0.90 to 1.13 ) & 1.12 (1.01 to 1.24$)$ & 1.12 (1.01 to 1.24$)$ & 1.15 (1.08 to 1.21$)$ & 1.15 (1.09 to 1.21$)$ \\
\hline $18: 00-19: 59$ & 1.21 (1.03 to 1.42 ) & 1.45 (1.25 to 1.67$)$ & 1.48 (1.31 to 1.66$)$ & 1.58 (1.45 to 1.73$)$ & 1.58 (1.41 to 1.77 ) & 1.65 (1.46 to 1.86 ) & 2.23 (1.97 to 2.52 ) & 2.42 (2.17 to 2.71$)$ & 2.40 (2.24 to 2.58 ) & 2.37 (2.18 to 2.59$)$ \\
\hline $20: 00-21: 59$ & 1.34 (1.11 to 1.61$)$ & 1.60 (1.36 to 1.89 ) & 1.71 (1.50 to 1.95 ) & 1.91 (1.74 to 2.09 ) & 1.81 (1.61 to 2.05 ) & 1.91 (1.70 to 2.14 ) & 2.68 (2.37 to 3.04 ) & 2.61 (2.32 to 2.93 ) & 2.54 (2.34 to 2.75 ) & 2.28 (2.07 to 2.51$)$ \\
\hline $22: 00-23: 59$ & 1.36 (1.12 to 1.65$)$ & 2.12 (1.79 to 2.49 ) & 2.18 (1.92 to 2.48$)$ & 2.85 (2.56 to 3.17$)$ & $2.20(1.92$ to 2.53$)$ & 1.89 (1.61 to 2.23$)$ & 2.68 (2.29 to 3.14 ) & 2.49 (2.16 to 2.86$)$ & 3.07 (2.75 to 3.42$)$ & 2.25 (2.08 to 2.43$)$ \\
\hline \multicolumn{11}{|l|}{ Females } \\
\hline $12: 00-1: 59$ & 1.35 (1.07 to 1.70$)$ & 3.26 (2.76 to 3.85 ) & 6.34 (5.34 to 7.51$)$ & 3.41 (3.06 to 3.80 ) & 3.86 (2.81 to 5.32 ) & 2.98 (2.62 to 3.38 ) & 4.54 (3.84 to 5.37 ) & 6.81 (5.72 to 8.10$)$ & 4.00 (3.70 to 4.32 ) & $5.13(4.60$ to 5.71$)$ \\
\hline $2: 00-3: 59$ & 2.26 (1.77 to 2.87 ) & 3.69 (3.06 to 4.44$)$ & 6.28 (5.15 to 7.66$)$ & 4.24 (3.78 to 4.76 ) & 4.78 (3.66 to 6.23 ) & 2.62 (2.16 to 3.19$)$ & 4.79 (4.12 to 5.57$)$ & 6.93 (5.92 to 8.12$)$ & 3.93 (3.57 to 4.33 ) & 4.47 (3.55 to 5.64$)$ \\
\hline $4: 00-5: 59$ & 1.45 (1.10 to 1.92$)$ & 3.03 (2.40 to 3.83 ) & 4.41 (3.71 to 5.25 ) & 2.66 (2.40 to 2.95$)$ & 1.86 (1.42 to 2.42$)$ & 1.34 (1.12 to 1.59$)$ & 2.57 (2.04 to 3.25$)$ & 3.14 (2.63 to 3.76$)$ & 1.76 (1.54 to 2.02$)$ & 1.40 (1.26 to 1.56$)$ \\
\hline $6: 00-7: 59$ & 1.80 (1.46 to 2.21$)$ & 2.43 (2.05 to 2.88 ) & 2.80 (2.41 to 3.26 ) & 2.38 (2.29 to 2.48 ) & $2.50(2.07$ to 3.00$))$ & 1.09 (0.95 to 1.25$)$ & 1.44 (1.26 to 1.63$)$ & 1.49 (1.32 to 1.67$)$ & 1.21 (1.14 to 1.28$)$ & 1.38 (1.28 to 1.48$)$ \\
\hline $8: 00-9: 59$ & 1.29 (1.06 to 1.57$)$ & $1.17(1.00$ to 1.36$)$ & 1.36 (1.15 to 1.61$)$ & 1.29 (1.20 to 1.39$)$ & 1.23 (1.05 to 1.43$)$ & 0.95 (0.87 to 1.05$)$ & 0.91 (0.82 to 1.01$)$ & 1.03 (0.95 to 1.11$)$ & 1.05 (1.01 to 1.09$)$ & 1.07 (1.01 to 1.13$)$ \\
\hline $10: 00-11: 59$ & 1.26 (1.07 to 1.48$)$ & 1.26 (1.09 to 1.44$)$ & 1.27 (1.07 to 1.50$)$ & 1.32 (1.25 to 1.39$)$ & 1.18 (1.00 to 1.39 ) & 1.05 (0.98 to 1.11$)$ & 1.04 (0.94 to 1.14$)$ & 1.07 (0.99 to 1.16$)$ & 1.10 (1.04 to 1.16$)$ & $1.12(1.05$ to 1.19$)$ \\
\hline $12: 00-13: 59$ & 000 & 000 & 000 & 000 & 000 & 000 & 000 & 000 & 000 & 000 \\
\hline $14: 00-15: 59$ & 1.07 (0.90 to 1.28$)$ & 0.99 (0.85 to 1.14$)$ & 1.06 (0.90 to 1.24$)$ & 1.14 (1.07 to 1.21$)$ & 1.07 (0.92 to 1.23$)$ & 0.96 (0.91 to 1.02 ) & 0.92 (0.83 to 1.01$)$ & 0.88 (0.82 to 0.94$)$ & 0.91 (0.87 to 0.95$)$ & 0.99 (0.95 to 1.04$)$ \\
\hline $16: 00-17: 59$ & $1.08(0.91$ to 1.27$)$ & $1.29(1.12$ to 1.48$)$ & 1.26 (1.10 to 1.44$)$ & $1.24(1.20$ to 1.29$)$ & $1.20(1.02$ to 1.40$)$ & $1.18(1.10$ to 1.26$)$ & 1.49 (1.36 to 1.64$)$ & 1.45 (1.36 to 1.55$)$ & 1.41 (1.34 to 1.48 ) & 1.50 (1.42 to 1.58$)$ \\
\hline $18: 00-19: 59$ & 1.63 (1.36 to 1.95$)$ & 2.09 (1.81 to 2.40$)$ & 2.21 (1.88 to 2.59 ) & 1.98 (1.87 to 2.09 ) & 1.94 (1.58 to 2.38 ) & 1.86 (1.74 to 1.98$)$ & 3.42 (3.11 to 3.78 ) & 3.60 (3.32 to 3.91$)$ & 2.99 (2.78 to 3.21$)$ & 2.95 (2.74 to 3.18$)$ \\
\hline $20: 00-21: 59$ & 1.84 (1.57 to 2.16$)$ & 2.45 (2.11 to 2.84 ) & 2.54 (2.15 to 2.99$)$ & 2.21 (2.07 to 2.36 ) & 2.51 (2.08 to 3.03$)$ & 2.50 (2.32 to 2.70$)$ & 3.96 (3.52 to 4.46$)$ & 3.90 (3.55 to 4.29 ) & 3.01 (2.86 to 3.16 ) & 3.43 (3.17 to 3.71$)$ \\
\hline $22: 00-23: 59$ & 1.88 (1.58 to 2.23$)$ & 3.15 (2.67 to 3.72 ) & 4.01 (3.38 to 4.75 ) & 2.89 (2.67 to 3.13$)$ & 3.52 (2.83 to 4.38 ) & 3.05 (2.74 to 3.39 ) & 4.59 (4.05 to 5.22 ) & 5.18 (4.57 to 5.87 ) & 3.37 (3.20 to 3.55 ) & 5.26 (4.83 to 5.73 ) \\
\hline
\end{tabular}


there is a clear pattern of elevated risk in the evening hours and the early morning hours. For the youngest men and women (ages 15-24), the relative risk differences over the $24 \mathrm{~h}$ clock are less substantial than for older age groups.

There are differences in the characteristics of injury events associated with work-related emergency department visits and lost-time compensation claims. In the emergency department data, the incidence rate for injuries arising from contact with objects or equipment is elevated relative to injuries arising from bodily reaction or exertion (see online supplemental figure S2). The opposite pattern is found in the characteristics of injury events in the lost-time claim data (see online supplemental figure S3). In all four injury risk estimate series, the risk of injury is elevated in the evening hours and the early morning hours.

A comparison of male and female incidence rates for workrelated emergency department visits and for lost-time claims over the $24 \mathrm{~h}$ clock are presented in online supplementary figures S4 and S5. For both men and women, the risk of injury is elevated in the evening hours and the early morning hours. This pattern is particularly strong for men presenting to emergency departments.

Table 3 presents incidence rates and relative risk estimates for lost-time claims over the $24 \mathrm{~h}$ clock for men and women in three occupational groups: occupations with substantial exposure to manual work, occupations with a mix of manual and non-manual tasks, and occupations predominantly engaged in non-manual tasks. The relative risk of a lost-time claim is elevated in the evening hours and the early morning hours for all three occupational groups and as expected, the incidence of lost-time compensation claims among workers in manual and mixed occupations is elevated relative to non-manual occupations.

Among women in manual occupations, hours worked between 18:00 and 08:00 represented 22.3\% of total hours and the proportion of all lost-time claims occurring in this period was $32.6 \%$ (table 3 ). For mixed occupations, the respective proportions were $14.0 \%$ and $25.1 \%$, and $19.0 \%$ and $24.3 \%$ for non-manual occupations. Among men in manual occupations, the time period between 18:00 and 08:00 represented $22.6 \%$ of total hours and generated $26.0 \%$ of all lost-time claims. For mixed occupations, the respective proportions were $22.1 \%$ and $28.6 \%$, and $16 \%$ and $24.8 \%$ for non-manual occupations. The fraction of lost-time compensation claims that can be attributed to the elevated risk of work injury in evening or night work schedules is $12.5 \%$ for women and $5.8 \%$ for men.

\section{DISCUSSION}

This study has described the incidence of work injury in Ontario over a 5 -year period by hour of the $24 \mathrm{~h}$ clock in two population-based administrative data sources. For men and for women and across all age groups, there was an elevated risk of work-related injury or illness in the evening, night and early morning periods documented in both administrative data sources used in this study. This elevated risk was consistently observed across manual, mixed and non-manual occupational groups in the workers' compensation administrative records.

In both administrative data sources, there is evidence that the relative risk of a work-related injury in the evening and night hours is higher for older men (aged 35-64) than younger men (aged 15-34) (table 2). This pattern may reflect age-related declines in capacity to adapt to non-standard work hours at older ages. ${ }^{31}$ An increase in the relative risk of work-related injury in the evening and night hours at older ages was not seen clearly in women.

At least two factors account for the higher incidence of workrelated injury and illness in the emergency department records in comparison with the workers' compensation claim records. This study has only included workers' compensation claim records that resulted in time off work (lost-time claims). Workers' compensation claims that only required health care services (no lost-time claims), representing 65\% of total accepted claims, have been excluded. In addition, approximately $30 \%$ of the Ontario labour force are in employment relationships that are excluded from coverage by the provincial workers' compensation insurance agency. On the other hand, incidence rate estimates will also differ in the two data sources due to alternate sources of medical care. Approximately 50\% of both lost-time and no lost-time claimants do not seek treatment in a hospital emergency department. ${ }^{22}$

Incidence rates per $200000 \mathrm{~h}$ worked were found to be broadly similar for the emergency department records and compensation claims during standard working hours (figure 1). In both data sources, incidence rates increased during the evening and night periods, with a more substantial increase observed in the emergency department records. The higher incidence rate in the emergency department records for evening and night periods may potentially be attributable to two factors. First, there are a broader range of medical care services available for the management of a work-related injury during the $08: 00$ $17: 00$ period, while, in contrast, there is very limited access to urgent medical care, other than in emergency departments, in the evening and night periods. Second, it is plausible that the risk of injuries arising from contact with objects and equipment is elevated in the evening and night hours. This class of injury events is most likely to present to emergency departments for urgent care.

The results of this parallel analysis of the incidence of work injury in Ontario over the $24 \mathrm{~h}$ clock in two population-based administrative data sources should be interpreted in light of the following limitations. Approximately $21 \%$ of lost-time claims were missing information on the time of the injury event and were excluded from the analyses reported in this paper. The incidence rates based on the lost-time claim records are therefore an underestimate and we do not know the incidence profile of the excluded records over the $24 \mathrm{~h}$ clock. Second, the study did not directly verify the accuracy of the time recorded on the administrative records of lost-time compensation claims or on the emergency department records. Third, we acknowledge that the triage time recorded on an emergency department record will be systematically later in time than the actual time of injury. The interval between the actual time of injury will be influenced by the severity of the injury, the travel distance from the workplace to the healthcare facility and, perhaps, by the period in the work shift when the injury occurs. We are currently conducting a linkage of records in the two administrative data sources to more fully understand the time interval differences in these two data sources. 3233

As noted in the Methods section of this paper, this study has made novel use of information from two Statistics Canada surveys to estimate the distribution of work hours over daytime, evening and night periods. The time use diary method applied in the GSS is a valid method for estimating working hours, ${ }^{28}$ however, there is the potential that sampling errors or respondent response errors may have underestimated work activity in the evening and night periods. The consequence of this 
Table 3 Lost-time claims in Ontario (2004-2008) by occupation and $2 \mathrm{~h}$ time intervals (rate per $200000 \mathrm{~h}$ )

\begin{tabular}{|c|c|c|c|c|c|c|c|c|c|c|c|c|}
\hline \multirow[b]{3}{*}{ Hour } & \multicolumn{12}{|c|}{ Occupation } \\
\hline & \multicolumn{4}{|l|}{ Manual } & \multicolumn{4}{|l|}{ Mixed } & \multicolumn{4}{|c|}{ Non-manual } \\
\hline & $\begin{array}{l}\text { Lost-time } \\
\text { claims }\end{array}$ & $\begin{array}{l}\text { Annual } \\
\text { hours }(000)\end{array}$ & Rate $(95 \% \mathrm{Cl})$ & RR $(95 \% \mathrm{Cl})$ & $\begin{array}{l}\text { Lost-time } \\
\text { claims }\end{array}$ & $\begin{array}{l}\text { Annual } \\
\text { hours (000) }\end{array}$ & Rate $(95 \% \mathrm{Cl})$ & RR (95\% Cl) & $\begin{array}{l}\text { Lost-time } \\
\text { claims }\end{array}$ & $\begin{array}{l}\text { Annual } \\
\text { hours (000) }\end{array}$ & Rate $(95 \% \mathrm{Cl})$ & RR $(95 \% \mathrm{Cl})$ \\
\hline \multicolumn{13}{|l|}{ Males } \\
\hline $12: 00-1: 59$ & 2610 & 149918.9 & 3.48 (3.35 to 3.62 ) & 2.11 (1.88 to 2.37 ) & 599 & 53784.5 & 2.23 (2.06 to 2.42 ) & 1.40 (1.25 to 1.56$)$ & 98 & 23897.8 & $0.82(0.67$ to 1.00$)$ & 2.77 (2.16 to 3.55$)$ \\
\hline $2: 00-3: 59$ & 2172 & 128752.9 & 3.37 (3.23 to 3.51 ) & 2.04 (1.75 to 2.38$)$ & 664 & 51641.2 & 2.57 (2.38 to 2.77 ) & 1.61 (1.44 to 1.81$)$ & 93 & 16352.4 & 1.14 (0.93 to 1.40$)$ & 3.84 (3.00 to 4.93$)$ \\
\hline $4: 00-5: 59$ & 2037 & 225382.5 & 1.81 (1.73 to 1.89 ) & 1.10 (0.96 to 1.25$)$ & 865 & 69943.5 & 2.47 (2.31 to 2.64$)$ & 1.55 (1.40 to 1.72 ) & 100 & 27069.7 & 0.74 (0.61 to 0.90$)$ & 2.50 (1.95 to 3.20$)$ \\
\hline $6: 00-7: 59$ & 7269 & 794553.5 & 1.83 (1.79 to 1.87$)$ & $1.11(1.00$ to 1.24$)$ & 2159 & 185950.6 & 2.32 (2.22 to 2.42$)$ & $1.46(1.32$ to 1.61$)$ & 342 & 128067.4 & $0.53(0.480 .59)$ & 1.80 (1.53 to 2.13$)$ \\
\hline $8: 00-9: 59$ & 17969 & 1645911.7 & 2.18 (2.15 to 2.21$)$ & $1.32(1.19$ to 1.48$)$ & 4163 & 434868.4 & 1.91 (1.85 to 1.97$)$ & 1.20 (1.11 to 1.31$)$ & 852 & 441080.3 & $0.39(0.36$ to 0.42$)$ & 1.31 (1.10 to 1.56$)$ \\
\hline $10: 00-11: 59$ & 22239 & 1810859.3 & 2.46 (2.43 to 2.49 ) & 1.49 (1.33 to 1.67$)$ & 5078 & 501756.6 & 2.02 (1.97 to 2.08 ) & 1.27 (1.16 to 1.40$)$ & 1124 & 530017.3 & $0.42(0.40$ to 0.45$)$ & 1.44 (1.21 to 1.70$)$ \\
\hline $12: 00-13: 59$ & 14098 & 1710475.8 & 1.65 (1.62 to 1.68$)$ & - & 3816 & 479249.9 & 1.59 (1.54 to 1.64$)$ & - & 724 & 489536.6 & $0.30(0.28$ to 0.32$)$ & - \\
\hline $14: 00-15: 59$ & 17457 & 1675132.8 & 2.08 (2.05 to 2.11$)$ & 1.26 (1.13 to 1.41$)$ & 3895 & 486050.0 & $1.60(1.55$ to 1.65$)$ & 1.01 (0.91 to 1.11$)$ & 899 & 503588.8 & $0.36(0.34$ to 0.38$)$ & 1.21 (1.04 to 1.40$)$ \\
\hline $16: 00-17: 59$ & 10308 & 1001028.3 & 2.06 (2.02 to 2.10$)$ & $1.25(1.10$ to 1.42$)$ & 2826 & 319295.6 & 1.77 (1.71 to 1.84$)$ & 1.11 (1.01 to 1.23$)$ & 543 & 300978.1 & $0.36(0.33$ to 0.39$)$ & 1.22 (1.06 to 1.41$)$ \\
\hline $18: 00-19: 59$ & 5800 & 488597.3 & 2.37 (2.31 to 2.43 ) & $1.44(1.31$ to 1.59$)$ & 1626 & 132845.6 & 2.45 (2.33 to 2.57 ) & 1.54 (1.40 to 1.69$)$ & 305 & 116251.4 & 0.52 (0.46 to 0.58$)$ & 1.77 (1.48 to 2.13$)$ \\
\hline $20: 00-21: 59$ & 4833 & 323102.2 & 2.99 (2.91 to 3.08 ) & 1.82 (1.64 to 2.01$)$ & 1158 & 87822.7 & 2.64 (2.49 to 2.80$)$ & 1.66 (1.51 to 1.81$)$ & 242 & 83352.6 & 0.58 (0.51 to 0.66$)$ & 1.96 (1.59 to 2.43$)$ \\
\hline $22: 00-23: 59$ & 4050 & 189243.6 & 4.28 (4.15 to 4.41$)$ & 2.60 (2.32 to 2.91$)$ & 869 & 56250.6 & 3.09 (2.89 to 3.30$)$ & 1.94 (1.76 to 2.14 ) & 189 & 38448.7 & $0.98(0.85$ to 1.13$)$ & 3.32 (2.69 to 4.09 ) \\
\hline \multicolumn{13}{|l|}{ Females } \\
\hline $12: 00-1: 59$ & 914 & 55516.6 & 3.29 (3.08 to 3.51$)$ & 2.08 (1.82 to 2.39$)$ & 184 & 27004.6 & 1.36 (1.18 to 1.57$)$ & 1.85 (1.50 to 2.28$)$ & 105 & 31025.6 & 0.68 (0.56 to 0.82$)$ & 2.61 (2.11 to 3.22 ) \\
\hline $2: 00-3: 59$ & 727 & 31263.7 & 4.65 (4.32 to 5.00$)$ & 2.56 (2.14 to 3.05$)$ & 198 & 21160.6 & 1.87 (1.63 to 2.15$)$ & 2.48 (2.11 to 2.92 ) & 89 & 24304.2 & $0.73(0.59$ to 0.90$)$ & 3.09 (2.46 to 3.87 ) \\
\hline $4: 00-5: 59$ & 815 & 30433.0 & $5.36(5.00$ to 5.74$)$ & 2.23 (1.92 to 2.58$)$ & 224 & 29909.9 & 1.50 (1.32 to 1.71$)$ & 1.79 (1.52 to 2.10$)$ & 115 & 44080.4 & 0.52 (0.43 to 0.62$)$ & 2.69 (2.19 to 3.30$)$ \\
\hline $6: 00-7: 59$ & 2617 & 93303.2 & 5.61 (5.40 to 5.83 ) & 2.02 (1.78 to 2.29$)$ & 690 & 146422.5 & 0.94 (0.87 to 1.01$)$ & 1.66 (1.46 to 1.87$)$ & 494 & 161743.0 & 0.61 (0.56 to 0.67$)$ & 2.40 (2.12 to 2.71$)$ \\
\hline $8: 00-9: 59$ & 4730 & 337979.2 & 2.80 (2.72 to 2.88 ) & 1.37 (1.20 to 1.56$)$ & 1681 & 581799.8 & $0.58(0.55$ to 0.61$)$ & 1.07 (0.95 to 1.22$)$ & 1227 & 507592.7 & $0.48(0.45$ to 0.51$)$ & 1.17 (1.06 to 1.29$)$ \\
\hline $10: 00-11: 59$ & 5806 & 472648.2 & 2.46 (2.40 to 2.52$)$ & $1.36(1.20$ to 1.55$)$ & 2304 & 719197.2 & 0.64 (0.61 to 0.67$)$ & 1.15 (1.05 to 1.26$)$ & 1490 & 604592.3 & $0.49(0.47$ to 0.52$)$ & 1.12 (1.02 to 1.22$)$ \\
\hline $12: 00-13: 59$ & 4249 & 500984.2 & 1.70 (1.65 to 1.75$)$ & - & 1915 & 675473.4 & 0.57 (0.55 to 0.60$)$ & - & 1284 & 577395.7 & 0.44 (0.42 to 0.46$)$ & - \\
\hline $14: 00-15: 59$ & 4444 & 495325.5 & 1.79 (1.74 to 1.84$)$ & $1.13(0.99$ to 1.29$)$ & 2094 & 667389.3 & $0.63(0.60$ to 0.66$)$ & 1.11 (1.00 to 1.22$)$ & 1350 & 565561.9 & $0.48(0.46$ to 0.51$)$ & 1.01 (0.92 to 1.11$)$ \\
\hline $16: 00-17: 59$ & 2863 & 354851.4 & 1.61 (1.55 to 1.67 ) & 1.23 (1.09 to 1.38$)$ & 1431 & 354122.3 & 0.81 (0.77 to 0.85$)$ & 1.30 (1.17 to 1.44$)$ & 920 & 287511.6 & 0.64 (0.60 to 0.68$)$ & 1.23 (1.12 to 1.35$)$ \\
\hline $18: 00-19: 59$ & 2226 & 204240.9 & 2.18 (2.09 to 2.27 ) & 1.78 (1.56 to 2.04$)$ & 914 & 132655.1 & 1.38 (1.29 to 1.47$)$ & $1.93(1.73$ to 2.15$)$ & 552 & 114026.2 & $0.97(0.89$ to 1.05$)$ & 1.92 (1.71 to 2.15$)$ \\
\hline $20: 00-21: 59$ & 1881 & 139021.5 & 2.71 (2.59 to 2.84 ) & 2.12 (1.88 to 2.39$)$ & 672 & 91775.0 & 1.46 (1.35 to 1.57$)$ & 2.11 (1.90 to 2.36 ) & 434 & 77467.1 & 1.12 (1.02 to 1.23$)$ & 2.31 (2.04 to 2.61$)$ \\
\hline $22: 00-23: 59$ & 1507 & 68647.9 & 4.39 (4.17 to 4.62$)$ & 2.82 (2.47 to 3.24$)$ & 283 & 43351.3 & 1.31 (1.17 to 1.47$)$ & 2.04 (1.77 to 2.34 ) & 230 & 38327.2 & 1.20 (1.05 to 1.37$)$ & 3.49 (2.99 to 4.08$)$ \\
\hline
\end{tabular}


potential bias would be an overestimate of the incidence of work injury in the evening and night periods.

There are recurring challenges in research on the relationship between work schedules and the risk of work injury. Among the methodological limitations of many existing studies are small sample sizes and restrictions to specific industries that limit the generalisability of study findings. ${ }^{6} 7$ The findings of this study are consistent with the results reported from the limited number of population-based studies that have observed work injury incidence for representative samples of workers in a range of occupational settings across the 24 h clock. ${ }^{6} 193435$ In these studies, the elevated risk of work injury on evening or night work schedules is not accounted for by differences in the age or occupational composition of workers.

While the incidence rate of work-related injury and illness is higher for men than for women in both of the population-based data sources applied in this study, we note that the relative risk of work injury in the evening, night and early morning periods does appear to be higher for women than for men, with the consequence that the fraction of all work injuries attributed to the excess risks of evening and night work is substantially higher for women than for men. A similar finding was reported in a recent Canadian study. ${ }^{8}$ Further research is required to understand the degree to which the higher relative risk experienced by women is due to composition differences in occupational exposure time to evening and night work schedules between men and women, differences in the pace of work, levels of supervision and co-worker support during non-daytime work schedules for occupations that have a dominant gender composition, or differences in non-work roles and responsibilities that may expose women to greater risk of fatigue on evening or night work schedules.

Despite the high prevalence of employment in non-daytime work schedules in all developed economies, the work injury hazards associated with evening and night schedules remain relatively invisible. While the risk of sleep disturbance from exposure to evening or night work schedules is generally well-recognised by many employers and voluntary guidelines are available to support optimal workplace practices concerning shift work schedules, ${ }^{36-38}$ there are very limited regulatory provisions in the developed economies defining occupational exposure limits for evening or night work schedules. ${ }^{39}$ This study has demonstrated the feasibility of using two administrative data sources to enhance capacity to conduct surveillance of work injury risk by time of day. The attributable fraction estimates associated with work in the evening and night hours reported in this study $(12.5 \%$ for women and $5.8 \%$ for men) are concordant with estimates recently reported for the Canadian labour force comparing workers employed in shift schedules to workers in regular daytime only schedules where the excess burden of work injury attributed to shift work was $14 \%$ for women and $8 \%$ for men. ${ }^{8}$ While more sophisticated aetiological research is needed to understand the specific mechanisms of hazards associated with non-regular work hours, the findings of this study suggest the importance of routine monitoring of work injury risk (estimating both events and the population at risk) over the $24 \mathrm{~h}$ clock by occupational health and safety authorities.

Contributors CAM, PS and CM conceived the study; CAM, PMS, AC and AB contributed to the design of the study methods and to the specification of data analysis; AC conducted analyses reported in this paper and contributed with CAM to the initial manuscript draft. All authors made editorial contributions to the final paper

\section{Competing interests None.}

Ethics approval The University of Toronto Research Ethics Board approved this study.
Provenance and peer review Not commissioned; externally peer reviewed.

Open Access This is an Open Access article distributed in accordance with the Creative Commons Attribution Non Commercial (CC BY-NC 3.0) license, which permits others to distribute, remix, adapt, build upon this work non-commercially, and license their derivative works on different terms, provided the original work is properly cited and the use is non-commercial. See: http://creativecommons.org/ licenses/by-nc/3.0/

\section{REFERENCES}

1 Williams C. Work-life balance of shift workers. Perspectives 2008;5-16.

2 Shields M. Shift work and health. Health Rep 2002:9:11-33.

3 Åkerstedt T. Shift work and disturbed sleep/wakefulness. Occup Med 2003:53:89-94

4 Frost P, Kolstad HA, Bonde JP. Shift work and the risk of ischemic heart disease-a systematic review of the epidemiological evidence. Scand J Work Environ Health 2009:35:163-79.

5 Schernhammer ES, Kroenke $\mathrm{CH}$, Laden $\mathrm{F}$, et al. Night work and risk of breast cancer. Epidemiology 2006;17:108-11.

6 Folkard S, Tucker P. Shift work, safety and productivity. OccupMed 2003;53:95-101.

7 Dembe AE, Erickson JB, Delbos RG, et al. Non standard shift schedules and the risk of job-related injuries. Scand J Work Environ Health 2006;32:232-40.

8 Wong IS, McLeod CB, Demers PA. Shift work trends and risk of work injury among Canadian workers. Scand J Work Environ Health 2011;37:54-61.

9 Levin L, Oler J, Whiteside JR. Injury incidence rates in a paint company on rotating production shifts. Accid Anal Prev 1985;17:67-73.

10 Smith L, Folkard S, Poole CJM. Increased injuries on night shift. Lancet 1994;344:1137-19.

11 Horwitz IB, McCall BP. The impact of shift work on the risk and severity of injuries for hospital employees: an analysis using Oregon workers' compensation data. Occup Med 2004:54:556-63.

12 Gold DR, Rogocz S, Bock N, et al. Rotating shift work, sleep, and accidents related to sleepiness in hospital nurses. Am J Public Health 1992;82:1011-14.

13 Smith MJ, Colligan MJ, Frockt IJ, et al. Occupational injury rates among nurses as a function of shift schedule. J Saf Res 1979;11:181-7.

14 Smith MJ, Colligan MJ, Tasto DL. Health and safety consequences of shift work in the food processing industry. Ergonomics 1982;25:133-44.

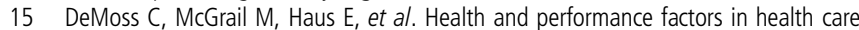
shift workers. J Occup Environ Med 2004;46:1278-81.

16 Pati AK, Chandrawanshi A, Reinberg A. Shift work: consequences and management. Curr Sci 2001;81:32-52.

17 Barreto SM, Swerdlow AJ, Smith PG, et al. A nested case-control study of fatal work related injuries among Brazilian steel workers. J Occup Environ Med 1997;54:599-604.

18 Novak R, Smolensky H, Fairchild E, et al. Shiftwork and industrial injuries at a chemical plant in southeast Texas. Chronobiol Int 1990;7:155-64.

19 Fathallah FA, Brogmus GE. Hourly trends in workers' compensation claims. Ergonomics 1999;42:196-207.

20 Smith L, Folkard S, Poole CJM. Increased injuries on the night shift. Lancet 1994;344:1137-9.

21 Caruso CC, Hitchcock EM, Dick RB, et al. Overtime and extended work shifts: recent findings on illnesses, injuries and health behaviors. National Institute for Occupational Safety and Health. DHHS Publication No. 2004-143 Cincinnati, OH, 212.

22 Mustard CA, Chambers A, McLeod C, et al. Comparison of data sources for the surveillance of work injury. J Occup Environ Med 2012;69:317-24.

23 Canadian Standards Association. Z-795-96 coding of work injury or disease information. Canadian Standards Association: Etobicoke, Ontario, 1996.

24 Canadian Institute for Health Information. National Ambulatory Care Reporting System Manual, 2008-2009 (Ottawa, CIHI, 2008).

25 Herbert F, Duguay $P$, Massicotte $P$, et al. Révision des catégories professionnelles utilisées dans les études de I'IRSST portant sur les indicateurs quinquennaux de lésions professionnelles. Report R-137. Montréal: Institut de reherche Robert-Sauvé en santé et en sécurité du travail (IRSST); 1996.

26 Statistics Canada. A guide to the Labour Force Survey. 71-543-GIE, 1-38. Ottawa: Statistics Canada, 2003.

27 Allan C, Dryburgh H, Horlor D. Canada's General Social Survey on Time Use: Challenges and Potential. November 2006. Statistics Canada. Catalogue no. 89-622-XIE, no. 3

28 Otterbach S, Sousa-Poza A. How accurate are German work-time data? A comparison of time-diary report and stylized estimates. Soc Indicators Res 2010;97:325-39

29 Smith PM, Mustard CA, Payne Jl. Methods for estimating the labour force insured by the Ontario Workplace Safety and Insurance Board: 1990-2000. Chronic DisCan 2004;25:127-37.

30 Breslin FC, Koehoorn M, Smith PM, et al. Age related differences in work injuries and permanent impairment: a comparison of workers' compensation claims 
among adolescents, young adults, and adults. J Occup Environ Med 2003;60: $1-6$.

31 Costa G, Di Millia L. Aging and shift work: a complex problem to face. Chronobiol Int 2008;25:165-81.

32 Boden LI, Ozonoff AL. Capture-recapture estimates of nonfatal workplace injuries and illnesses. Ann Epidemiol 2008;18:500-6.

33 Rosenman KD, Kalush A, Reilly MJ, et al. How much work-related injury and illness is missed by the current national injury surveillance system. J Occup Environ Med 2006;48:357-65.

34 Fortson KN. The diurnal pattern of on-the-job injuries. Monthly Labour Review September 2004;127:18-25.
35 Akerstedt T. Work injuries and time of day-national data. Shiftwork Int News/ 1995; 12:2.

36 Occupational Health Clinics for Ontario Workers. Shift work, health effects and solutions. 2005. http://www.ohcow.on.ca/resources/handbooks/shiftwork/shiftwork. pdf

37 Saskatchewan Labour. Managing shift work. Occupational Health and Safety Division. 1998. http://www.labour.gov.sk.ca

38 Canadian Centre for Occupational Health and Safety. Rotation shift work. 1998. http://www.ccohs.ca/oshanswers/ergonomics/shiftwrk.html

39 Dembe A. Ethical issues relating to the health effects of long working hours. J Business Ethics 2009;84:195-208. 